\title{
Survey of the Level of Preparedness and Fears of Anaesthesia Staff regarding the Management of COVID-19 patients in ABUTH Zaria-Nigeria
}

Saidu Yusuf Yakubu ( $\nabla$ saiduyakubu@yahoo.com )

Ahmadu Bello University Teaching Hospital Zaria Nigeria

\section{Research Article}

Keywords: Level of preparedness, fears, anaesthesia, staff, management of COVID-19

Posted Date: October 23rd, 2020

DOI: https://doi.org/10.21203/rs.3.rs-97257/v1

License: (1) (1) This work is licensed under a Creative Commons Attribution 4.0 International License.

Read Full License 


\section{Abstract}

Objectives: Data was collected to determine the level of preparedness and fears of anaesthesia staff regarding the management of COVID-19 patients in a low resource tertiary hospital in Zaria, Nigeria. Information obtained was used to request for missing equipment from the hospital management and to allay the fears of staff during the COVID-19 pandemic.

Results: Data reported was from the survey of consenting anaesthesia staff at the Ahmadu Bello University Teaching Hospital Zaria. Information obtained include age, gender, marital status, professional role, level of preparedness, availability of working materials/equipment, fear of COVID-19, level of stress, stigmatization and the willingness or otherwise to volunteer in the management of COVID-19 patients. All 45 respondents stated that they do not have a life insurance. Forty four $(97.8 \%)$ lack access to COVID-19 testing while $36(80 \%)$ have not received any training on COVID-19 and the use of personal protective equipment. Twenty eight of 43 staff said that they were not willing or prepared to participate in the management of COVID-19 patients. Data will be useful to other researchers with a similar challenge. Data obtained was deposited at https://dx.doi.org/10.17632/stdmys22gk.1.

\section{Introduction}

Coronavirus disease 2019 (COVID-19) is a respiratory infection caused by a novel coronavirus first observed in Wuhan China in December 2019 [1]. Some developed countries were caught unaware by the disease and faced lack of ICU beds among others [2]. The challenge was worse in Africa due to inadequate number of health personnel, intensive care units and ventilators. The high level of poverty, overcrowding and infectious diseases such as malaria, HIV and tuberculosis further complicated things [3]. The Johns Hopkins Center for Health Security publication reported Africa as least prepared among other continents to respond to health emergencies, provide treatment for the sick and protection for health personnel [4]. The fear being entertained by health workers in Nigeria concerning COVID-19 is because of shortage of protective equipment in hospitals and poor infection prevention and control policy [5]. Studies have shown that healthcare staff in COVID-19 treatment centres suffers stigmatization from friends and family members due to fear of contracting the disease [6, 7]. A study in Nigeria reported that "over $65 \%$ of healthcare workers strongly agreed that their willingness to go to work has been affected by the COVID-19 pandemic". They went further to state that "majority of participants 162 (54\%) went to work four days in a week during this pandemic in comparison to 226 (75.33\%) who went to work for five days during the pre-Covid-19 period" [5]. This data was collected to determine the level of preparedness and fears of anaesthesia staff regarding the management of COVID-19 patients in a low resource tertiary hospital in Zaria, Nigeria. Information obtained was used to request for missing equipment from the hospital management, address shortcomings and to allay the fears of staff during the COVID-19 pandemic. Data was not published in a research paper because of lack of funds for publication. 


\section{Methods}

During the period April 11-18, 2020 structured questionnaires were sent out by WhatsApp to physician anaesthetists, nurse anaesthetists, intensive care nurses, biomedical engineers and health assistants in Ahmadu Bello University Teaching Hospital Zaria, Nigeria and those who consented filled and returned the questionnaires. Requirement for Ethics approval was waived by the Ahmadu Bello University Teaching Hospital Ethics Committee to enable documentation of the situation of things in anaesthesia department ABUTH Zaria during the COVID-19 pandemic. All participants of the survey consented to the filling of questionnaires and reporting of findings.

Data obtained include age, gender, marital status, professional role, level of preparedness, availability of working materials/equipment, fear of COVID-19, level of stress, stigmatization and the willingness or otherwise to volunteer in the management of COVID-19 patients. Information collected were analyzed using SPSS version 21. The level of significance was set at $p<0.05$.

\section{Results}

Fifty questionnaires were sent out and 45 responses were received. The Mean Age SD of participants were 40.25 9.62. The age group of respondents was as shown in Figure 1 (Data file 1 in Table 1) [8]. The demographic characteristics of respondents were as in Table 2 in the legend. There were 22 (48.9\%) females and $23(51.1 \%)$ males. All 45 respondents stated that they have no life insurance. Forty four (97.8\%) lack access to COVID-19 testing while 36 (80\%) have not received any training on COVID-19 and the use of personal protective equipment (PPE) as shown in Table 3 in the legend. The Table 3 in Data file 1 of Table 1 showed that while $32(71.1 \%)$ of staff agreed that they have hand sanitizers for use at work $43(95.6 \%)$ indicated that other PPE's for use while on duty were inadequate $(p<0.001)$ [8]. In addition, $90 \%$ of respondents said that there are no enough ventilators and other necessary equipment for the management of COVID-19 patients in the health facility (Figure 2) [8]. Regarding the fear of COVID-19 forty participants expressed the concern of being infected while on duty $(p<0.001)$ as shown in Table 4 [8]. Twenty three (51.1\%) of staff stated that they have become stressed up during the COVID-19 pandemic (Figure 3) while Table 5 showed the various ways they respond to stress [8]. Thirty two (71.1\%) respondents reported that family members did not avoid associating with them because of fear of contracting the disease $(p=0.007)$. Twenty eight of 43 staff said that they were not willing or prepared to participate in the management of COVID-19 patients as shown in Table 6 [8].

\section{Discussion}

This study found that no staff in the department had a life insurance and almost all lack access to COVID-19 testing. Majority of staff had also not received training on the disease and the use of personal protective equipment. In a similar study by Ogolodom and co-workers on the Knowledge, Attitudes and Fears of Healthcare Workers towards the Corona Virus Disease pandemic in South-South, Nigeria; authors reported that $61 \%$ of healthcare workers saw themselves at the risk of being infected with COVID-19 while 
$62 \%$ of them indicated that there was inadequate safety in the hospital coupled with lack of insurance policy which posed a challenged to the efficient care of patients [5]. Our study involved the staff of anaesthesia department in one institution while the work of Ogolodom and colleagues was multi-center that involved various categories of healthcare workers which adds to the strength of their findings. The level of knowledge of a disease has been shown to affect ones understanding of the risk of contracting the disease [9]. The same situation applies to COVID-19. Receiving training on the disease by healthcare workers will assist in empowering them with the necessary skills for safety precautions to take while treating patients to avoid being infected. Majority of our staff had no PPE for use while on duty as at the time of study. The importance of provision of PPE's for use while treating COVID-19 patients cannot be over emphasized. The same applies for the availability of ventilators to manage critically ill patients. The World Economic Forum reported in March 2020 that Africa has the lowest capacity to providing critical and intensive care in the world [10]. Half of our staff reported being stressed up during the pandemic with only one third who witnessed stigmatization from family members. The reverse was the case in a study by Uvais et al on COVID-19 related stigma and perceived stress among dialysis staff. They documented that $54.6 \%$ of participants suffered significant stigma while $36.1 \%$ had stress. Their study had 335 respondents compared to ours that had only 45 participants. Two thirds of staffs in anaesthesia were not willing to participate in the management of COVID-19 because of fear of infection and lack of safety, protection and working facilities. This is an indication that the hospital needs to be proactive in the provision of working materials and being ready for emergency situations such as COVID-19.

\section{Conclusion}

This survey showed that majority of staff had no life insurance, lack access to COVID-19 testing and did not receive any training on the disease and the use of PPE. While a significant number of them expressed the fear of being infected with COVID-19 only half became stressed up during the pandemic with about two thirds not willing to participate in the management of infected patients.

\section{Limitations}

The data obtained cannot be generalized to other hospitals. It only described the situation at the Ahmadu Bello University Teaching Hospital Zaria, Nigeria as at April 2020.

\section{Abbreviations}

ABUTH: Ahmadu Bello University Teaching Hospital

PPE: Personal Protective Equipment

\section{Declarations}

\section{Ethics approval and consent to participate}

Requirement for Ethics approval was waived by the Ahmadu Bello University Teaching Hospital Ethics 
Committee to enable documentation of the situation of things in anaesthesia department ABUTH Zaria during the COVID-19 pandemic. All participants of the survey consented to the filling of questionnaires and reporting of findings.

\section{Consent for publication}

Not applicable

\section{Availability of data material}

The data described in this note can be freely and openly accessed on Mendeley Data, V1, doi: 10.17632/stdmys22gk.1. Please see table 1 and reference list for details and links to the data.

\section{Competing interests}

No conflicts of interest to declare

\section{Funding}

No funding was received for this survey

\section{Authors' contributions}

Dr Saidu Y Yakubu conceived, designed the survey, administered questionnaires and prepared the manuscript

\section{Authors Information}

Dr Saidu Yusuf Yakubu, MBBS, DA, FWACS is a Senior Lecturer and Consultant Anaesthetist at the Ahmadu Bello University (ABU)/Ahmadu Bello University Teaching Hospital (ABUTH) Zaria, Nigeria. He has been the Head of Anaesthesia in ABU/ABUTH Zaria since 2017.

Dr Yakubu is a Fellow of the West African College of Surgeons (FWACS) and Member of the International Association for the Study of Pain (IASP).

He has interest in Pain Management, Patient Blood Management and Critical Care.

\section{Acknowledgements}

I wish to thank all the participants of this survey and those who assisted in one way or the other.

\section{References}

1. Team NCPERE. Vital surveillances: the epidemiological characteristics of an outbreak of 2019 novel coronavirus diseases (COVID-19) - China. China CDC Weekly. 2020; 2(8):113-22.

2. Rosenbaum L. Facing COVID-19 in Italy-ethics, logistics, and therapeutics on the epidemic's front line. N Engl J Med. 2020; 382:1873-1875.

DOI: 10.1056/NEJMp2005492. 
3. Lucero-Prisno, D.E., Adebisi, Y.A. \& Lin, X. Current efforts and challenges facing responses to 2019nCoV in Africa. g/ob health res policy 2020; 5: https://doi.org/10.1186/s41256-020-00148-1

4. Johns Hopkins Center for Health Security. Global Health Security Index. https://www.ghsindex.org/wp-content/uploads/2019/10/2019-Global-Health-Security-Index.pdf. Accessed on 13 September 2020.

5. Ogolodom MP, Mbaba AN, Alazigha N, Erondu OF, Egbe NO, et al. Knowledge, Attitudes and Fears of HealthCare Workers towards the Corona Virus Disease (COVID-19) Pandemic in South-South, Nigeria. Health Sci J. 2020; Sp. 1:002.

6. Uvais NA, Shihabudheen P, Bishurul Hafi NA. Perceived stress and stigma among doctors working in COVID-19-designated hospitals in India. Prim Care Companion CNS Disord 2020; 22(4):20br02724.

7. Uvais, N.A., Aziz, F. \& Hafeeq, B. COVID-19-related stigma and perceived stress among dialysis staff. J Nephrol (2020). https://doi.org/10.1007/s40620-020-00833-x.

8. Yakubu, Saidu (2020), "Survey of the Level of Preparedness and Fears of Anaesthesia Staff regarding the Management of COVID-19 patients in ABUTH Zaria-Nigeria". https://dx.doi.org/10.17632/stdmys22gk.1

9. Janjua NZ, Razaq M, Chandir S, Rozi S, Mahmood B. Poor knowledge - Predictor of nonadherence to universal precautions for blood borne pathogens at first level care facilities in Pakistan. BMC Infectious Diseases 2007; 7:1-11.

10. World Economic Forum. https://www.weforum.org/agenda/2020/03/why-sub-saharan-africa-needsa-unique-response-to-covid-19/ Accessed 19 Apr 2020.

\section{Tables}

Table 1: Overview of data files/data sets.

\begin{tabular}{|llll|}
\hline Label & Name of data file/data set & $\begin{array}{l}\text { File types } \\
\text { (file } \\
\text { extension) }\end{array}$ & $\begin{array}{l}\text { Data repository and identifier (DOI or } \\
\text { accession number) }\end{array}$ \\
\hline $\begin{array}{l}\text { Data } \\
\text { file 1 }\end{array}$ & $\begin{array}{l}\text { Survey of the Level of } \\
\text { Preparedness and Fears of } \\
\text { Anaesthesia Staff regarding the } \\
\text { Management of COVID-19 } \\
\text { patients in ABUTH Zaria-Nigeria }\end{array}$ & MS Word & https://dx.doi.org/10.17632/stdmys22gk.1 \\
\hline
\end{tabular}

Table 2: Demographic Characteristics of Respondents 


\begin{tabular}{|lll|}
\hline Characteristics & Frequency & Percent \\
\hline Gender & & \\
\hline Female & 22 & 48.9 \\
\hline Male & 23 & 51.1 \\
\hline Total & 45 & 100.0 \\
\hline Marital Status & & \\
\hline Single & 11 & 24.4 \\
\hline Married & 34 & 75.6 \\
\hline Total & 45 & 100.0 \\
\hline Professional role & & \\
\hline Health Assistant & 5 & 11.1 \\
\hline Biomedical & 6 & 13.3 \\
\hline ICU Nurses & 11 & 24.4 \\
\hline Anaesthetic Nurses & 4 & 8.9 \\
\hline Registrar & 8 & 17.8 \\
\hline Senior Registrar & 7 & 15.6 \\
\hline Consultant & 1 & 2.2 \\
Not indicated & 3 & 6.7 \\
\hline Total & 45 & 100.0 \\
\hline
\end{tabular}

Table 3: Level of preparedness of respondents in the institution 
Level of preparedness

Do you have a life insurance policy

No

Yes

Total

Do you have access to testing for COVID-19

No

Yes

Total

Do you currently take elective operations in your centre

No

Yes

Total

Do you currently take emergency operations in your centre

No

Yes

Total

Have you received any training on COVID-19/use of personal protective equipment(PPE) in your facility

No

Yes

Total

Do you regularly update yourself with relevant online information/resources on COVID-19

No

Yes

Total
44

1

45

35

10

45

5

38

43

11.6

88.4

100.0

\section{Figures}

Figures 1-3 are available for viewing via the dataset link provided in the paper. 